\title{
Merino sheep of the South Island high-country: past, present and future
}

\author{
W.H. SUTHERLAND \\ Benmore Station, Private Bag, Omarama, New Zealand \\ bill.kate@farmside.co.nz
}

The Merino sheep is synonymous with the New Zealand high-country and always has been since it was first introduced in the early 1800 s. They have been wandering the hills and mountain of the South Island since then.

\section{Past}

Until relatively recently the profitability of highcountry merino farms has largely been determined by the size of the wool cheque. With this acting as the main economic driver the sheep selection process has mostly been focused on maximising wool fleece value. This has been achieved by improving the volume of the wool through selection for increased wool weight and by improving the value of the wool by selecting a lower fibre diameter to improve quality, style and staple strength of the fleece.

In those days, the meat values of animals were minimal and large wether flocks were retained with negligible selection pressure on growth and reproduction. Those were also the days when labour was plentiful on high-country runs.

\section{Present}

With the dramatic change in meat values and the intensification of high-country farming, and the introduction of irrigation, the way merino sheep are farmed has changed. Over the last 20 years there has been a dramatic shift towards a dual-purpose merino sheep, which produces the wool it is famed for, but also can be fattened. On many merino sheep farms and in most financial years, the net proceeds of wool are matched by those received from the sale of finished and store stock. This dramatic change has largely been achieved through improved nutritional management, particularly of twin-bearing ewes, plus an important change via the genetic gains being made in the breed. (Figure 1).With the advent of muscle and fat scanning by ultrasound and the positive selection pressure on these traits as well as growth traits, the ability of the merino to maintain condition score is being dramatically improved. These changes have also resulted in greater weaning percentages and lamb growth rates (Figure 2)

The reputation of New Zealand merino wool has also grown exponentially thanks to the efforts of The New Zealand Merino Company, who market $75 \%$ of New Zealand merino wool. By taking an early stance on ensuring the best animal welfare and reducing the environmental footprint, the company has created increased value for both merino wool growers and the brands that utilise this precious fibre.

In a time when strong wool prices are at a historical low, the prices for merino wool have rarely been better. It really is boom time within the New Zealand merino industry at the moment.

\section{The future}

With unprecedented interest in New Zealand merino wool the future of the industry is bright, however, in saying that, it is not the time for the industry to get complacent. This is the time to build more resilient and profitable farms with lower chemical use and higher welfare standards than ever before.

To do this, the industry will rely heavily on the use of genetic tools to evolve the merino as an increasingly robust animal that can be farmed outside of the highcountry. One of the key factors that will unlock the potential of the merino industry is the adaptation of the breed to be resistant to foot rot. We have made great inroads on this front over the last 5 years. With the help of a number of key bodies such as Merino Inc., New Zealand Merino and The Ministry for Primary Industries, we are close to having an Estimated Breeding Value (EBV) for foot rot. Already, we have seen the power this EBV will have within the merino central progeny test. The EBV currently being developed utilises the best of both quantitative genetics and genomics to identify the animals within the flock that are the most resistant to foot rot.

Breeding values on some 33000 New Zealand merino sheep have been generated as a result of inspecting hundreds of thousands of sheep feet. These EBVs were generated by scientists working in Australia who are using the latest technology and methods in single step genetic analysis. While it is not a 'silver bullet' and will take time for the industry to find and multiply the resistance of foot rot for these animals, it is the first time we have the right tools and a group of breeders that have the skills to use these tools to combat this problem.

The future of the merino industry will be based on the dual production of high value wool and meat. The animal that requires less labour to farm and is more resilient to climatic variability will need to be 
developed. This type of animal will be resistant to foot rot and internal parasites and will be robust in all environments. Ultimately, this will mean the merino and fine wool industry will expand out of the highcountry into a wider range of farming environments.

\section{Merino in the Upper Waitaki}

The merino sheep was first introduced to New Zealand by Captain James Cook in 1773. In 1834 John Bill imported 102 merinos to Manu Island from New South Wales, and 4 years

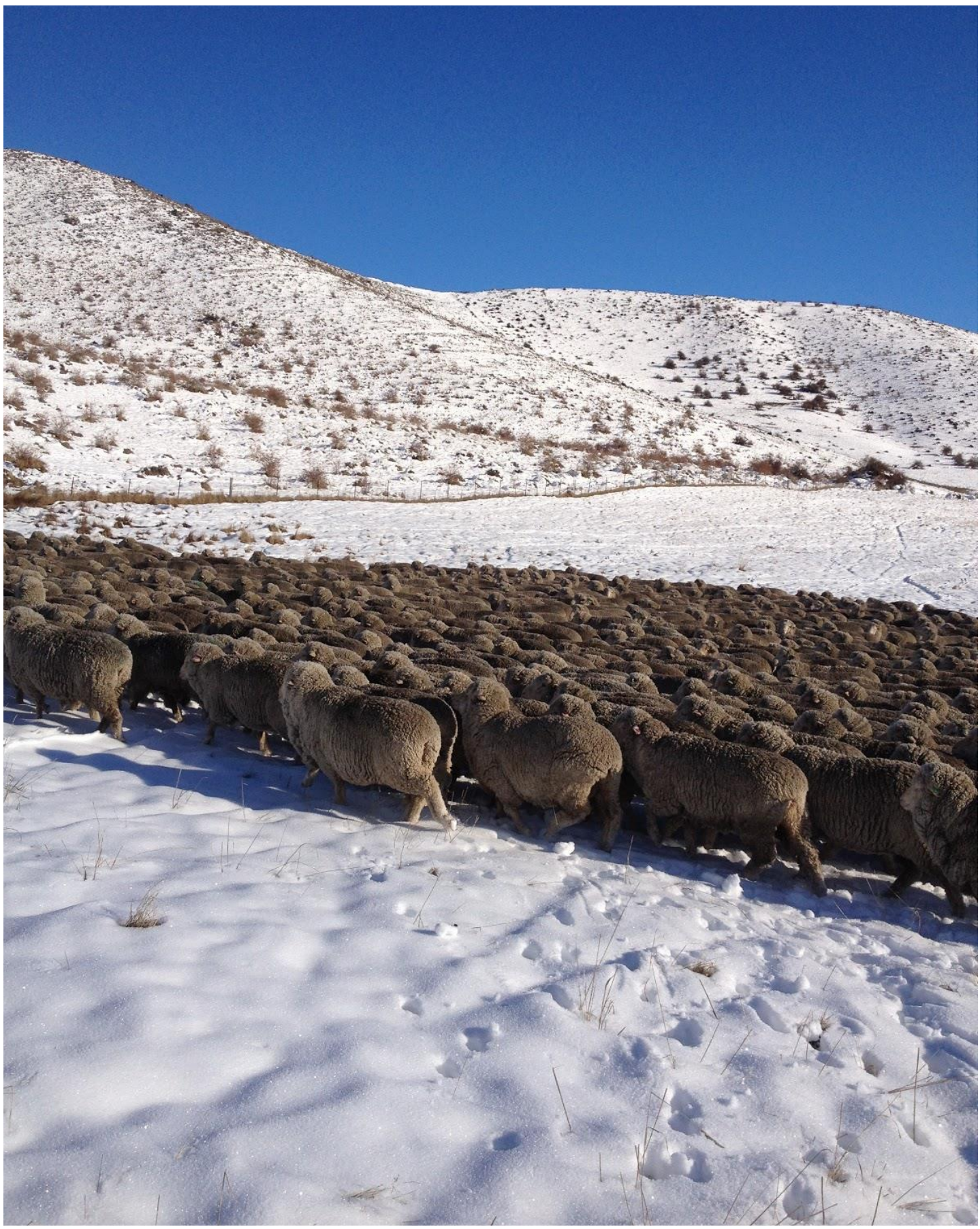

Figure 1 Merino ewes in snow after pregnancy scanning. 


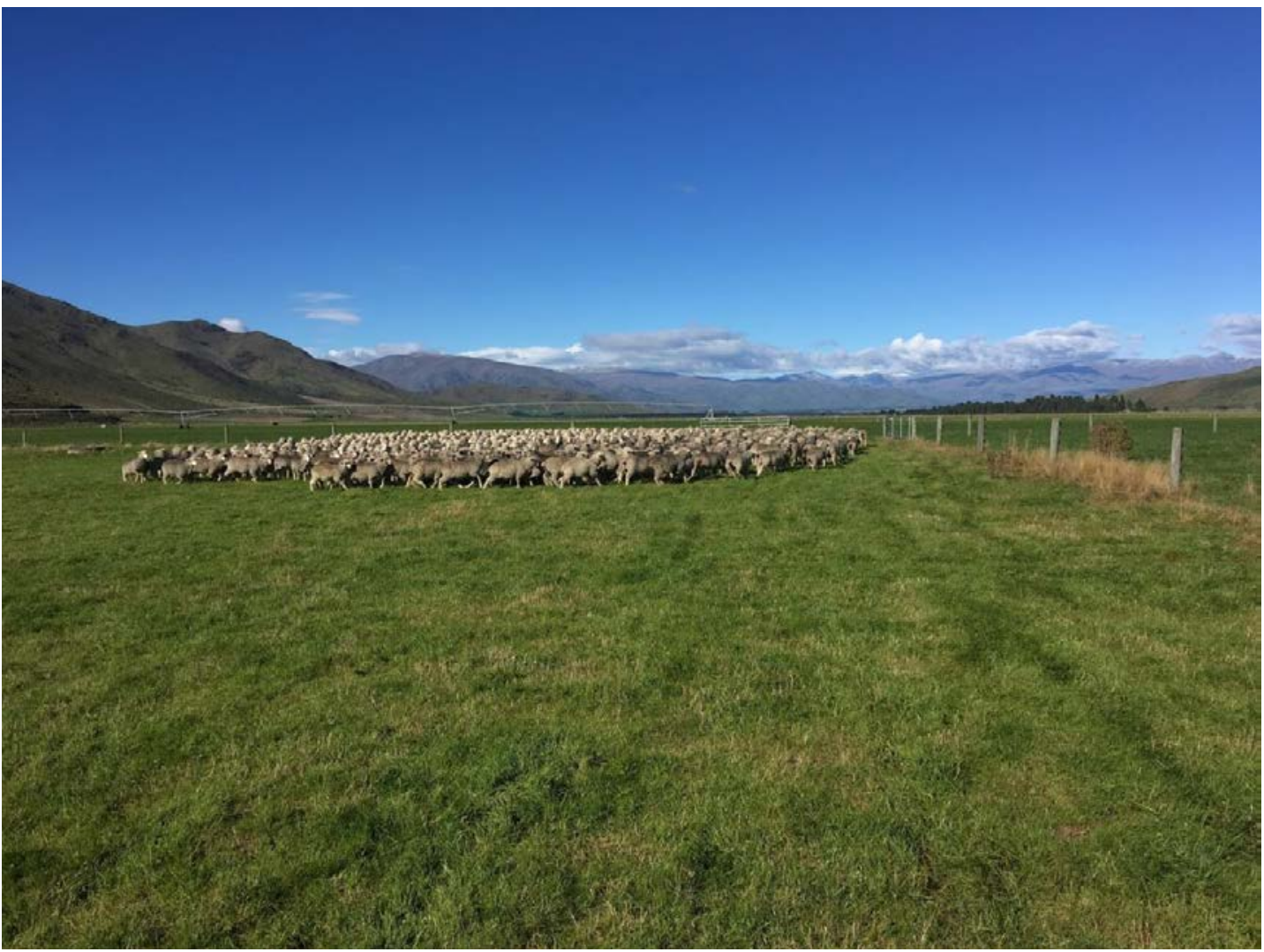

Figure 2 Weaned merino lambs on irrigated pasture.

later he exported four bales of merino wool to Sydney. In 1887 there were 334000 merino sheep and by 1914, 496000 in the Mackenzie/Waitaki basin. The main selling venues were the Omarama and Tekapo saleyards. In 1911, the first merino sheep sale was held on Mt John Station, owned then by Walter Black. It remained at this location until 1929 when the Tekapo saleyards were opened and where 17000 sheep were sold in the first sale. This sale expanded with 29000 sheep sold in 1937. In the 1940s through to 1963, Omarama publican, Ian Woods, owned the Omarama saleyards. During this time the Omarama Saleyards Company was established and built a yard able to hold 30000 sheep and 200 calves. In 1972, the Omarama saleyards were the first to weigh calves on sale day. The last 1-day sheep sale of 42000 lambs and ewes was conducted in 1990, and in 1991, a separate lamb sale was held a week before the adult sheep sale.

Historically, New Zealand merino wool was scoured and shipped to Bradford, England, for sale. Nowadays, $75 \%$ of fine wool is marketed through the New Zealand Merino Company which has brand partners such as Icebreaker, Reda, NKK, Smartwool and Lora Pana to name a few. The merino breed is known for its hardiness, survivability and foraging capabilities in tough conditions like the high-country. Before the major land development in the Mackenzie Basin in the mid-1960s the majority of the stations were truly native blocks with tussock, fescue and browntop plant covers. Merino flocks were run on these stations for their ability to produce high quality wool on meagre rations. Production figures were poor by today's standards - three kilograms fleece weight and $60 \%$ lambing. Most stations only bred enough animals to replace their ewe and wether flocks. Wether flocks were often larger than the ewe flocks and wethers were often grazed on higher less productive country. The early 1970 s saw the start of land development on better soils (higher $\mathrm{pH})$ along with topdressing. Rabbits were still a major problem in this era leaving little feed for stock. With land development came a major shift in wool production with higher wool weights and larger sheep being bred.

However, with these developments came large challenges for animal health, in terms of their worm resistance, tolerance of foot rot and general management practices. The merino has a wide range of wool types (ultra-fine, super-fine, fine, medium and strong). These range in micron, crimp and strength, the finer the wool 
generally the lower the micron. Tractability of animals using EID (Electronic Identification) tags is an example of technology used today for identification of individual sheep data (Figure 3).

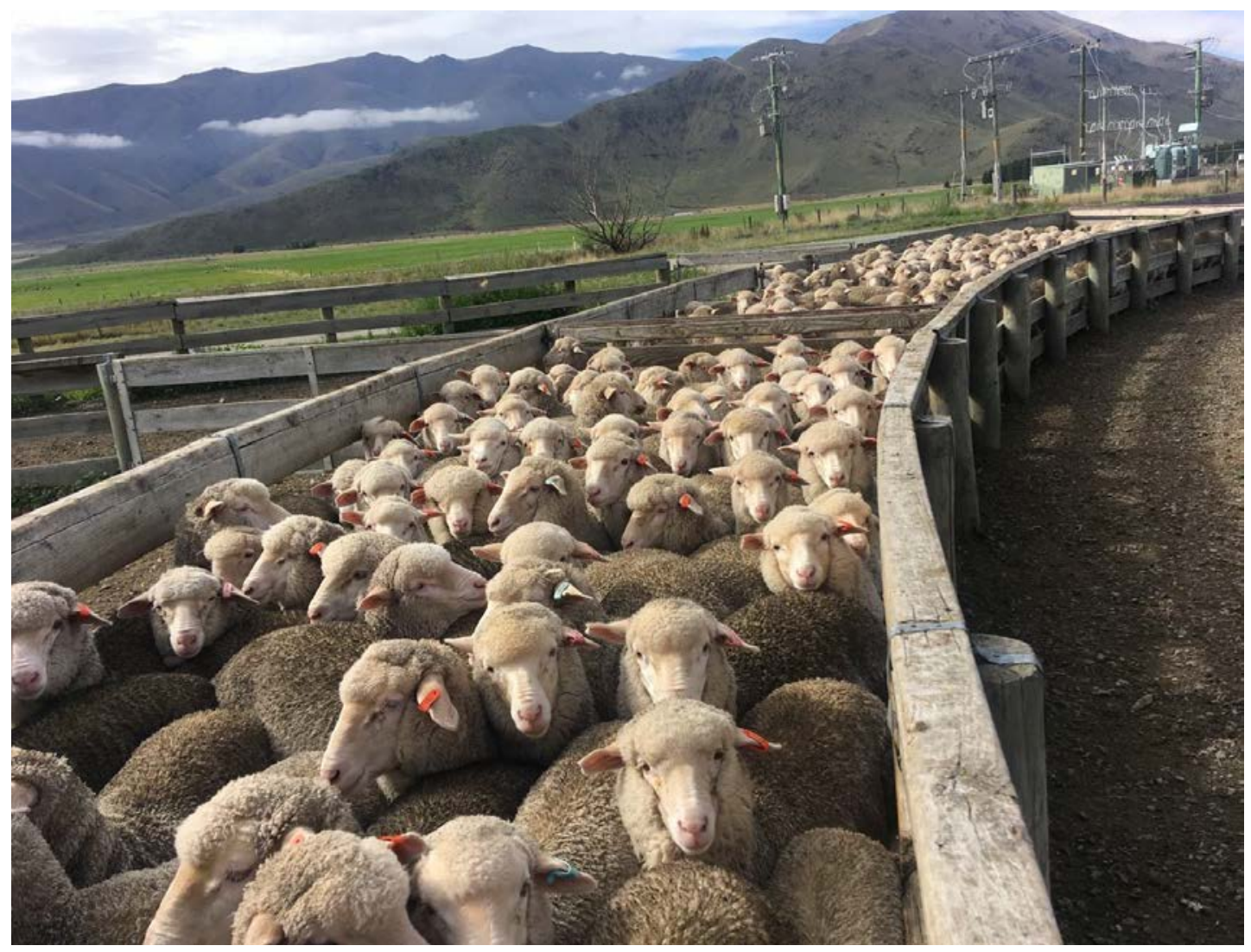

Figure 3 Weaned lambs showing EID tags 